\title{
A novel method for ionizing radiation-induced RNA damage detection by poly(A)-tailing RT-PCR
}

\author{
TIE Yi ${ }^{1}$, HU Zheng ${ }^{1}$, LÜ GuiXiang ${ }^{1,2}$, FU HanJiang ${ }^{1}$, XING RuiYun ${ }^{1}, Z^{2} H U J^{1}{ }^{1}$, \\ SUN ZhiXian ${ }^{1} \&$ ZHENG XiaoFei ${ }^{1 *}$ \\ ${ }^{1}$ Department of Biochemistry and Molecular Biology, Beijing Institute of Radiation Medicine, Beijing 100850, China; \\ ${ }^{2}$ Department of Biochemistry and Molecular Biology, Basic Medical Science College, Harbin Medical University, Harbin 150086, China
}

Received June 27, 2011; accepted August 4, 2011

\begin{abstract}
Ionizing radiation (IR) causes severe cellular damage both directly and indirectly and disrupts RNA integrity. RNA strand breaks are the most frequent type of damage caused by IR. RNA damage is involved in the development of degenerative diseases, including Alzheimer's disease and Parkinson's disease. However, the mechanism of mRNA damage and any resulting pathophysiological outcomes are poorly understood. This is partly because there is a lack of sensitive tools to monitor damage randomly occurring in RNA, especially RNA strand break damage in a given RNA. In this work, a method using the reverse transcription polymerase chain reaction (RT-PCR) after poly(A) addition to 3'-end of RNA to determine RNA strand break damage in a specific RNA by poly(A) polymerase has been developed. The levels of damage in specific mRNAs, including ABL1, TP53, GADD45A and $A T R$ from IR-treated HeLa cells were examined. Strand breaks were detected in all mRNAs examined. The study provides a novel and sensitive method based on 3'-end poly(A)-tailing RT-PCR to monitor RNA strand break damage.
\end{abstract}

RNA damage, RNA strand break, ionizing radiation, poly(A) polymerase, RT-PCR

Citation: $\quad$ Tie Y, Hu Z, Lü G X, et al. A novel method for ionizing radiation-induced RNA damage detection by poly(A)-tailing RT-PCR. Chinese Sci Bull, 2011, 56: 3172-3177, doi: 10.1007/s11434-011-4721-7

Nucleic acid-damaging agents, such as radiation, carcinogens, reactive oxygen species, chemotherapy drugs and nitrogen species, cause damage to DNA and RNA molecules $[1,2]$. The role of DNA damage in the development of cancers, age-related disorders and other diseases has been intensively studied [3]. However, RNA damage has not received sufficient attention, and the potential deleterious effects of RNA damage have not been widely appreciated. Under radiation stress, increased levels of reactive oxygen species (ROS) may cause increased RNA oxidative damage and may result in the strand breaks. Strand breaks or oxidative damage to protein-coding RNAs or non-coding RNAs might cause errors in protein synthesis or dysregulation of gene expression [4-6]. Recently, prevention of increases in oxidation-damaged RNA products was reported in patients

*Corresponding author (email: xfzheng100@126.com) of degenerative diseases, including Parkinson's disease, Alzheimer's disease, dementia with Lewy bodies, and atherosclerosis [7-16]. In aged rats, the level of oxidationdamaged RNA is higher than that of young rats [17].

There are several methods to detect oxidative lesions. Currently, the most reliable method to measure RNA oxidation is quantification of 7,8-Dihydro-8-oxoguanine (8oxoguanine; 8-oxo-G) by high-performance liquid chromatography (HPLC) together with mass spectroscopy. However, this approach detects only one oxidized lesion in RNA and requires a relatively large quantity of RNA (usually 10-200 $\mu \mathrm{g}$ ). It cannot be used to measure damage of a given RNA among total RNA preparations [18-21]. Northwestern blotting and immunoprecipitation with a monoclonal antibody for 8-oxo-G have also been employed to monitor the levels of oxidized RNA. Since nucleic acids can be further oxidized after isolation, these antibody-based methods may 
introduce further oxidation damage in vitro and high levels of expertise are required to distinguish them. Moreover, the above methods only detect 8 -oxo-G, whose content may vary under different conditions compared with other RNA lesions. Gong et al. [22] developed a method using reverse transcription followed by PCR to detect RNA damage caused by oxidative stress. This method is based on the fact that a heavily oxidized RNA template generates pretermination of the cDNA chain during reverse transcription, and applicable for oxidative damage. With this method, they found that RNA damage occurs randomly in $16 \mathrm{~S}$ rRNA.

Ionizing radiation (IR) is an important modality used in the treatment of malignancy and is one example of an agent that induces oxidative genotoxic stress. Both DNA and RNA are damaged by IR. Strand breaks, together with base modifications of RNA, may also be produced after IR treatment [23,24]. Better understanding of RNA strand break damage and its possible pathological consequences depends on the availability of efficient methodologies to determine the levels of damage.

The method described in this work aims to detect RNA strand break damage with high sensitivity and specificity. We have developed a new method that involves the addition of polyA tails to RNAs followed by RT-PCR. We have tested this method by determining the level of damage in 4 selected mRNA molecules from a preparation of total RNAs isolated from IR-treated cells. Our method is based on the addition of poly(A) to the terminus of the broken RNA and on the use of oligo(dT)-universal primers to produce cDNAs. Specific mRNAs are then further amplified with a general polyA primer together with a specific primer for each mRNA. The amplified DNA products can be detected directly by gel electrophoresis. This method should be useful for the detection of damage in specific RNA molecules with strand breaks.

\section{Materials and methods}

\subsection{Cell culture and treatments}

HeLa cells (human cervical carcinoma cells) were maintained in DMEM (GIBCO BRL, USA) containing 10\% FBS with $100 \mathrm{U} / \mathrm{mL}$ penicillin and $100 \mathrm{mg} / \mathrm{mL}$ streptomycin in a humidified atmosphere of $5 \% \mathrm{CO}_{2}$ at $37^{\circ} \mathrm{C}$. Cells were plated into $100 \mathrm{~mm}$ dishes and incubated for $24 \mathrm{~h}$. Cells were then treated while in logarithmic growth with ionizing radiation at different doses and for different lengths of time.

\subsection{Irradiation of cultured cells}

HeLa cells were irradiated with ${ }^{60} \mathrm{Co}$ at a dose of 208.08 cGy/min. Cells RNA were immediately extracted after IR. Cells were irradiated with total doses, as indicated. The radiation doses were chosen to cover a wide range, from a low dose (1 Gy) to high doses (20 Gy).

\subsection{Collection and preparation of RNA}

Cells were collected at various times after radiation, as indicated in the figure legends. Cells were rinsed in PBS, directly lysed using Trizol reagent (Sigma, USA) and total RNA was isolated using a standard phenol chloroform extraction method according to the manufacturer's protocol. RNA was quantified using a GeneQuant pro spectrophotometer (GeneQuant, USA).

Total RNA samples were subjected to a $6 \%$ polyacrylamide gel electrophoresis (PAGE) $2 \mu \mathrm{g}$ per lane, stained with silver staining methods. Briefly, the gels were first washed once for 1 min with deionized water and fixed in $10 \%$ ethanol, $0.5 \%$ acetic acid for $10 \mathrm{~min}$ at room temperature. Then color impregnation lasted for $10 \mathrm{~min}$ at room temperature with $0.1 \%$ silver nitrate. The gels were then washed twice for $20 \mathrm{~s}$ with deionized water; then color development was for 2 to $10 \mathrm{~min}$ with a mixture of $0.1 \mathrm{~mol} / \mathrm{L}$ sodium hydroxide, $0.056 \%$ formaldehyde. The color reaction was stopped with $10 \%$ ethanol, $0.5 \%$ acetic acid.

\section{4 cDNA synthesis}

Total RNA was first polyadenylated by poly(A) polymerase (Ambion, USA). Polyadenylation reactions $(50 \mu \mathrm{L})$ were set up with $10 \mu \mathrm{g}$ total RNA and $1 \mu \mathrm{L}(2 \mathrm{U})$ poly(A) polymerase according to the manufacturer's protocol. The reaction was incubated at $37^{\circ} \mathrm{C}$ for $60 \mathrm{~min}$. After incubation, poly(A)tailed total RNA was recovered by phenol/chloroform extraction and ethanol precipitation. Reverse transcription was performed using $1 \mu \mathrm{g}$ poly(A)-tailed total RNA and an excessive molar amount $(1.5 \mu \mathrm{mol} / \mathrm{L})$ of RT primer $\left(5^{\prime}\right.$ gcgagcacagaattaatacgactcactatagg(t)18VN-3'). The mixtures of RNA and RT primer were incubated at $65^{\circ} \mathrm{C}$ for $5 \mathrm{~min}$ to denture the RNA and then transferred on ice to anneal the primers to the RNA templates. The following components were then added: $5 \times$ cDNA synthesis buffer, $40 \mathrm{U}$ of RNase Out, and $15 \mathrm{U}$ of ImproII Reverse Transcriptase (Promega). The total volume of the reverse transcription reactions was $20 \mu \mathrm{L}$. The mixtures were incubated at $42^{\circ} \mathrm{C}$ for $60 \mathrm{~min}$ and then at $70^{\circ} \mathrm{C}$ for $15 \mathrm{~min}$ to terminate the reactions. PCR was performed following the instructions of the $2 \times$ Taq PCR StarMix(GenStar, Beijing). One PCR primer was mRNA specific and the other was a universal primer which was complementary to the RT primer (Figure 1).

\subsection{PCR and gel assay}

PCR was performed with the indicated primers (for PCR primer pairs and products, see Table 1). PCR reactions $(20 \mu \mathrm{L})$ contained $2 \mu \mathrm{L}$ cDNA, $0.5 \mu \mathrm{mol} / \mathrm{L}$ of each primer, $1 \times$ Taq polymerase premixture buffer (Genstar). Reaction conditions were: 1 cycle at $94^{\circ} \mathrm{C}$ for $3 \mathrm{~min} ; 35$ cycles at $94^{\circ} \mathrm{C}$ for $30 \mathrm{~s}, 68^{\circ} \mathrm{C}$ for $30 \mathrm{~s}$, and $72^{\circ} \mathrm{C}$ for $2 \mathrm{~min}$; and 1 
RNA treated by damaging agent

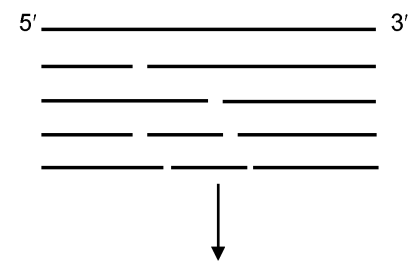

Polyadenylated by poly $(A)$ polymerase

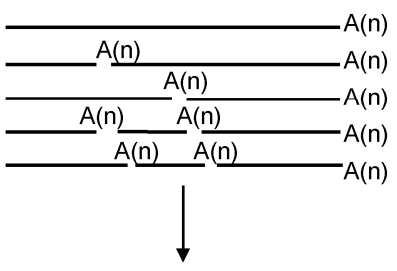

Reverse transcription
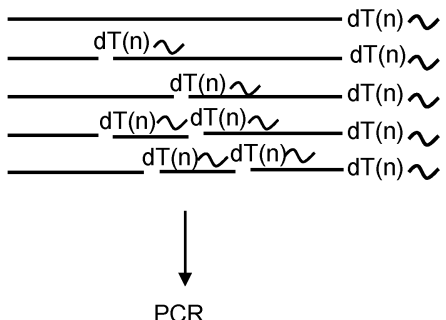

Gene specific primer

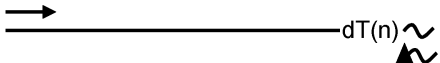

universal tag primers

Gel electrophoresis

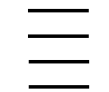

Figure 1 Poly(A)-tailling RT-PCR analysis of RNA damage.

Table 1 Specific primers for selected mRNAs

\begin{tabular}{lcl}
\hline Gene function & Gene name & Primer sequence $\left(5^{\prime} \rightarrow 3^{\prime}\right)$ \\
\hline Cell cycle arrest & gadd45a & gggaggcagcggcccaatta \\
Cell cycle checkpoint & $t p 53$ & cagtcagatcctagcgtcgag \\
Cell cycle checkpoint & $a t r$ & gaggagtttggcctccac \\
Apoptosis & $a b l 1$ & atgttggagatctgcctgaagctg \\
Universal primer & & attctagaggccgaggcggccgacatg \\
\hline
\end{tabular}

cycle at $72^{\circ} \mathrm{C}$ for $10 \mathrm{~min}$. PCR products and DNA markers were resolved on a $2 \%$ agarose gels, which were then stained with ethidium bromide.

\subsection{The design process}

The method of 3' poly(A) tailing followed by RT-PCR has been previously used to map and identify the $3^{\prime}$-ends of a relatively homogeneous pool of RNAs. Eberding et al. [25] used this method to identify mRNA degradation intermedi- ates in vivo. Our laboratory has also used this method to monitor miRNA expression [26]. In this paper, we applied this method to detect mRNA strand breaks. Base on the observation that IR-induced RNA damage causes stalling or arrest of reverse transcription, we aimed to examine the amounts of cDNA products that are extended to various lengths using untreated or IR-treated RNA as templates. If damage occurs randomly in treated RNA, the RNA will be broken into fragments shorter than the intact RNA. Briefly, this method involves the addition of $\mathrm{A}$ residues to the 3 '-ends of all RNA molecules followed by reverse transcription with an oligo(dT) primer to generate a population of cDNAs corresponding to all of the poly(A)-tailed RNA fragments in the population. The cDNA is then PCR amplified using a universal RT primer and specific primer to the mRNA of interest. The resulting products are then separated on an agarose gel. The protocol is summarized in Figure 1. To test the efficacy of this method, the cDNA products of IR-treated HeLa cells were prepared and examined using PCR.

\section{Results}

\subsection{RNA damage induced by ionizing radiation}

RNA damage was induced in cultured cells by IR and RNA integrity was then examined. HeLa cells were treated with ionizing radiation and total RNA samples were subjected to polyacrylamide gel electrophoresis (PAGE). As shown in Figure 2, we found that shortened RNAs were produced after IR treatment, observed as a smear of RNA in each lane, and that the degree of shortening (increased smearing) was enhanced as the dose of ionizing radiation increased. This

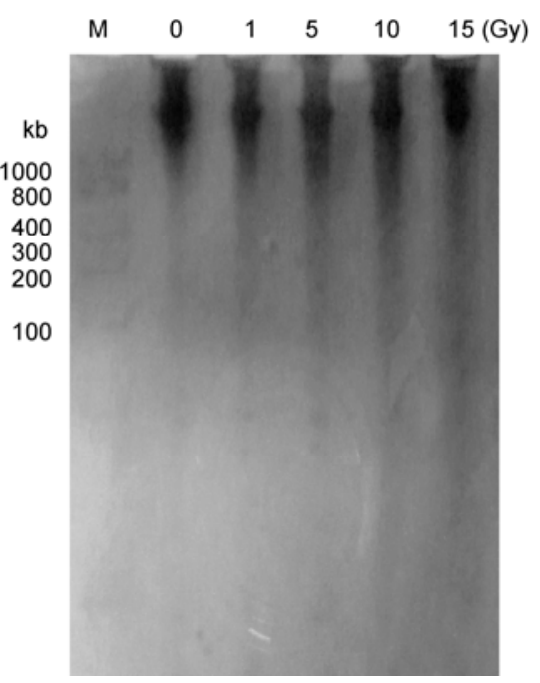

Figure 2 RNA damage was induced by in vitro ionizing radiation and total RNA was analyzed by PAGE. HeLa cells were untreated or treated with ionizing radiation of the indicated doses. Total RNA was prepared and separated on a $6 \%$ PAGE gel. The gel was stained with silver. A 25 bp RNA ladder (Promega) was used as a size marker. M, Marker. 
indicated that strand breaks occurred in a proportion of RNAs during IR treatment and that the RNA damage became more severe as the dose of ionizing radiation increased.

\subsection{Poly(A)-tailling RT-PCR detection of ionizing radiation-induced RNA damage}

Total RNA from HeLa cells treated with ionizing radiation of different doses was polyadenylated by poly(A) polymerase, and cDNA was synthesized from each RNA sample using an oligo(dT)-universal primer by reverse transcription. The mRNAs of irradiation response-related genes, including ATR, ABL1, GADD45A and $p 53$ were analyzed.

The amplified DNA ladders of GADD45A, TP53, ATR and $A B L 1$ showed that the extent of damage to these mRNAs was different. In Figure 3(a)-(d), the PCR amplification of bands showed that the different dose of IR $(1,5$, 10 and $15 \mathrm{~Gy}$ ) can induce RNA strand break of $A T R, A B L 1$, TP53, GADD45A, respectively. In Figure 3(e) and (f), the results showed that the RNA damage of $A B L 1$ and TP53 can be kept at least $24 \mathrm{~h}$ or more. These ladder profiles were different in the different genes and reflected the different damage that is characteristic of these genes.

\section{Discussion}

There are only 3 or 4 methods to detect RNA damage, as described in the introduction; however, these approaches measure only one oxidized lesion in RNA and they do not detect RNA strand breaks.

Here, we have used the 3 '-end poly(A)-tailing polymerase chain reaction method to detect RNA strand break damage. We selected several genes which regulation IR reaction to detected mRNA strand break damage. $G A D D 45 A$, was first cloned as a member of the GADD (growth arrest and DNA damage-inducible) genes. The $G A D D 45 A$ gene has been implicated in stress signaling in response to physiological or environmental stressors that result in either cell cycle arrest or DNA repair [27]. TP53 is a well known tumor suppressor. Somatic mutations in the TP53 gene are one of the most frequent alterations in human cancers TP53 mutations are also potential prognostic and predictive markers [28]. The non-receptor tyrosine kinase, Abl1, localizes to the nucleus and cytoplasm and is activated by cellular stress. Abl1 plays a prominent role in tumor igenesis. $\mathrm{BCR} / \mathrm{ABL}$ is present in most chronic myelogenous leukemia (CML) patients and in acute lymphocytic leukemia (a)

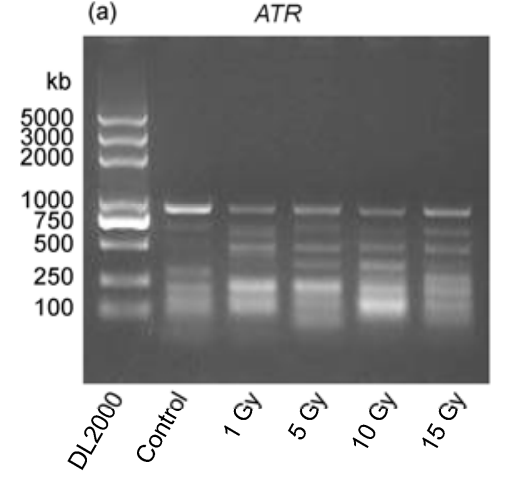

(d)

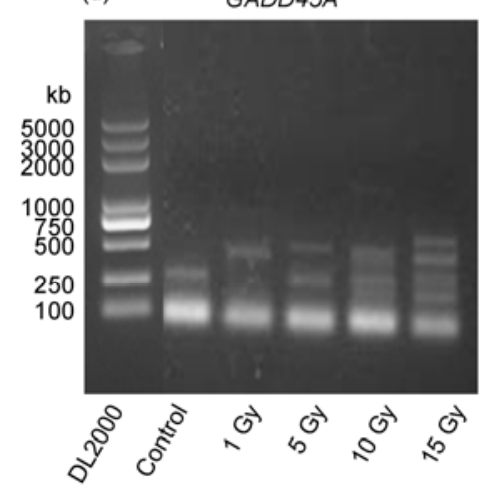

(b)
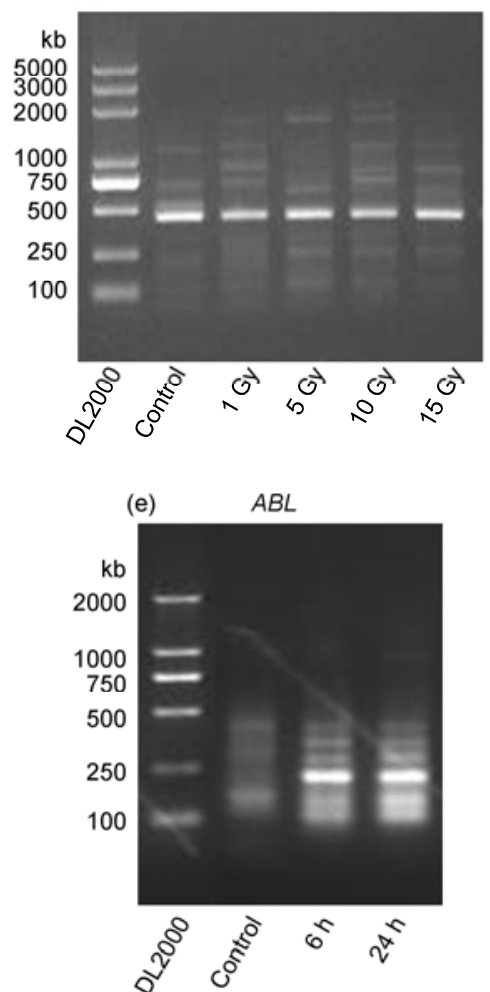

(c)
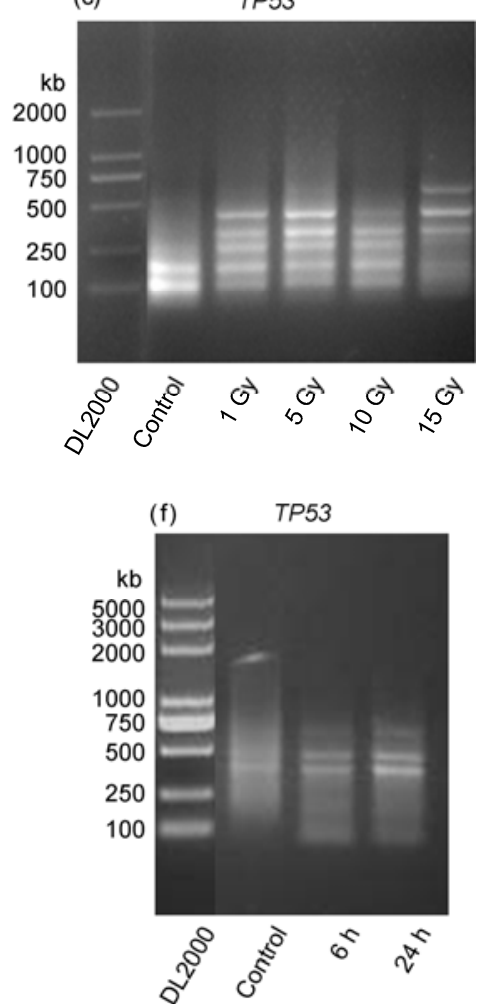

Figure 3 PCR amplification of different cDNAs from IR-damaged RNA. RNA was harvested from HeLa cells treated with different doses of IR or from cells at different times after irradiation with a dose of $8 \mathrm{~Gy}$. RNA was extracted and tailed with poly(A) and reverse transcribed. The resulting cDNAs were then amplified by PCR using a universal primer and specific primers for the different mRNAs, as indicated in the figure. PCR products were electrophoresed in a $1 \%$ agarose gel followed by visualization with ethidium bromide. DL2000 DNA molecular marker indicates quantity of PCR products. 
(ALL) patients. TEL/ABL results from a $t(9 ; 12)$ translocation reported in ALL, acute myelogenous leukemia (AML) and atypical CML [29-32]. This 3'-end poly(A)-tailing PCR technique has been used in $5^{\prime} \mathrm{RACE}$, the detection of mRNA degradation intermediates and miRNA expression detection. Eberding et al. [25] detected mRNA degradation intermediates in tissues using the $3^{\prime}$-end poly(A)-tailing polymerase chain reaction method. We previously used the $3^{\prime}$-end poly(A)-tailing polymerase chain reaction method to monitor the expression of microRNAs [26]. In this study, using poly(A)-tailing PCR, we have revealed significant laddering of cDNAs derived from certain RNAs after IR-treatment of cultured cells. This suggested that damage occurs with different susceptibilities on different mRNAs and causes cDNA pretermination. This method has proven to be useful in determining RNA damage caused by ionizing radiation. In addition, the method can also be used to determine the location of break sites in mRNAs by sequencing the PCR products. Moreover, poly(A)-tailing PCR, enables the determination of damage levels of a specific mRNA. The RNA damage we detected is most likely to reflect strand breaks caused directly by ionizing radiation. In contrast to known approaches, such as capillary electrophoresis or specific sequence RT-PCR which only detects oxidative damage, our method can successfully detect RNA strand break damage. This is important because strand break damage is more deleterious than base modification.

Different types of DNA damage are induced by IR treatments, such as DNA double strand breaks, single strand breaks and oxidation damage. However, there are few reports concerning types of RNA damage and their consequences. As we described above, oxidative stress can cause hydrogen modification to DNA or RNA and affect translation and protein synthesis. In this work, we analyzed PCR products from IR-treated HeLa cells; however, our method is applicable to the detection of RNA strand break damage in other systems. This method may also be useful for determining any other changes in RNA that produce RNA tailing, such as the production of mRNA splicing isoforms, RNA strand breakage caused by chemical reagents or RNA degradation.

This work was supported by the National Basic Research Program of Chi$n a$ (2007CB914601, 2010CB912801) and Beijing Municipal Natural Science Foundation (5112029).

1 Aas P A, Otterlei M, Falnes P O, et al. Human and bacterial oxidative demethylases repair alkylation damage in both RNA and DNA. Nature, 2003, 421: 859-863

2 Shen Z, Wu W, Hazen S L. Activated leukocytes oxidatively damage DNA, RNA, and the nucleotide pool through halidedependent formation of hydroxyl radical. Biochemistry, 2000, 39: 5474-5482

3 Ames B N, Gold L S. Endogenous mutagens and the causes of aging and cancer. Mut Res, 1991, 250: 3-16

4 Newton D L, Kaur G, Rhim J S, et al. RNA damage and inhibition of neoplastic endothelial cell growth: Effects of human and amphibian ribonucleases. Radiat Res, 2001, 155: 171-174
5 Bellacosa A, Moss E G. RNA repair: Damage control. Curr Biol, 2003, 13: R482-R484

6 Hofer T, Badouard C, Bajak E, et al. Hydrogen peroxide causes greater oxidation in cellular RNA than in DNA. Biol Chem, 2005, 386: $333-337$

7 Shan X, Lin C L. Quantification of oxidized RNAs in Alzheimer's disease. Neurobiol Aging, 2005, 27: 657-662

8 Shan X, Tashiro H, Lin C L. The identification and characterization of oxidized RNAs in Alzheimer's disease. J Neurosci, 2003, 23: 4913-4921

9 Nunomura A, Perry G, Pappolla M A, et al. RNA oxidation is a prominent feature of vulnerable neurons in Alzheimer's disease. J Neurosci, 1999, 19: 1959-1964

10 Nunomura A, Perry G, Hirai K G, et al. Neuronal RNA oxidation in Alzheimer's disease and Down's syndrome. Ann N Y Acad Sci, 1999, 893: 362-364

11 Abe $\mathrm{T}$, Tohgi $\mathrm{H}$, Isobe $\mathrm{C}$, et al. Remarkable increase in the concentration of 8-hydroxyguanosine in cerebrospinal fluid from patients with Alzheimer's disease. J Neurosci Res, 2002, 70: 447-450

12 Zhang J, Perry G, Smith M A, et al. Parkinson's disease is associated with oxidative damage to cytoplasmic DNA and RNA in substantia nigra neurons. Am J Pathol, 1999, 154: 1423-1429

13 Nunomura A, Chiba S, Kosaka K, et al. Neuronal RNA oxidation is a prominent feature of dementia with Lewy bodies. Neuroreport, 2002, 13: 2035-2039

14 Tateyama M, Takeda A, Onodera Y, et al. Oxidative stress and predominant Ab42(43) deposition in myopathies with rimmed vacuoles. Acta Neuropathol (Berl.), 2003, 105: 581-585

15 Martinet W, deMeyer G R, Herman A G, et al. Reactive oxygen species induce RNA damage in human atherosclerosis. Eur J Clin Invest, 2004, 34: 323-327

16 Ding Q, Markesbery W R, Chen Q, et al. Ribosome dysfunction is an early event in Alzheimer's disease. J Neurosci, 2005, 25: 9171-9175

17 Liu J, Head E, Gharib A M, et al. Memory loss in old rats is associated with brain mitochondrial decay and RNA/DNA oxidation: Partial reversal by feeding acetyl- $L$-carnitine and/or $R$-a-lipoic acid. Proc Natl Acad Sci USA, 2002, 99: 2356-2361

18 Fiala E S, Conaway C C, Mathis J E. Oxidative DNA and RNA damage in the livers of Sprague-Dawley rats treated with the hepatocarcinogen 2-nitropropane. Cancer Res, 1989, 49: 5518-5522

19 Shen Z, Wu W, Hazen S L. Activated leukocytes oxidatively damage DNA, RNA, and the nucleotide pool through halidedependent formation of hydroxyl radical. Biochemistry, 2000, 39: 5474-5482

20 Hofer T, Badouard C, Bajak E, et al. Hydrogen peroxide causes greater oxidation in cellular RNA than in DNA. Biol Chem, 2005, 386: 333-337

21 Rhee Y, Valentine M R, Termini J. Oxidative base damage in RNA detected by reverse transcriptase. Nucleic Acids Res, 1995, 23: 3275-3282

22 Gong X, Tao R, Li Z. Quantification of RNA damage by reverse transcription polymerase chain reactions. Anal Biochem, 2006, 357: $58-67$

23 Wurtmann E J, Wolin S L. RNA under attack: Cellular handling of RNA damage. Crit Rev Biochem Mol Biol, 2009, 44: 34-49

24 Fimognari C, Sestili P, Lenzi M, et al. RNA as a new target for toxic and protective agents. Mutat Res, 2008, 648: 15-22

25 Eberding A, Rehaume V, Lee C H. Detection of mRNA degradation intermediates in tissues using the $3^{\prime}$-end poly(A)-tailing polymerase chain reaction method. Anal Biochem, 2004, 335: 58-65

26 Fu H, Tie Y, Xu C, et al. Identification of human fetal liver miRNAs by a novel method. FEBS Lett, 2005, 579: 3849-3854

27 Liebermann D A, Hoffman B. Gadd45 in the response of hematopoietic cells to genotoxic stress. Blood Cells Mol Dis, 2007, 39: 329-335

28 Zhan Q, Lord K A, Alamo I, et al. The gadd and MyD genes define a novel set of mammalian genes encoding acidic proteins that synergistically suppress cell growth. Mol Cell Biol, 1994, 14: 2361-2371

29 Ozaki T, Nakagawara A. p53: The attractive tumor suppressor in the cancer research field. J Biomed Biotechnol, 2011, 2011: 603925 
Epub 2010 Dec 6

30 Slupianek A, Hoser G, Majsterek I, et al. Fusion tyrosine kinases induce drug resistance by stimulation of homology-dependent recombination repair, prolongation of $\mathrm{G}(2) / \mathrm{M}$ phase, and protection from apoptosis. Mol Cell Biol, 2002, 22: 4189-4201
31 Hantschel O, Superti-Furga G. Regulation of the c-Abl and Bcr-Abl tyrosine kinases. Nat Rev Mol Cell Biol, 2004, 5: 33-44

32 Zheng X, Oancea C, Henschler R, et al. Reciprocal $t(9 ; 22)$ ABL/BCR fusion proteins: Leukemogenic potential and effects on B cell commitment. PLoS One, 2009, 4: e7661

Open Access This article is distributed under the terms of the Creative Commons Attribution License which permits any use, distribution, and reproduction in any medium, provided the original author(s) and source are credited. 